\title{
Colour Stability of Methyl Methacrylate Denture Base Materials after Exposure to Arabian Coffee
}

\section{Nehad $H^{*}$}

Department of Prosthodontics, Prince Sattam Bin Abdulaziz University, Saudi Arabia Department of Removable Prosthodontics, Al-Azhar University, Egypt

*Corresponding author: Nehad Harby, Department of Prosthodontics, College of Dentistry, Prince Sattam Bin Abdulaziz University, Alkharj, Saudi Arabia; Department of Removable Prosthodontics, Faculty of Dental and Oral Medicine, Al-Azhar University, Cairo, Egypt, Tel: +966552364232; Email: n.harby@psau.edu.sa

\section{Research Article}

Volume 5 Issue 1

Received Date: January 02, 2020

Published Date: January 21, 2020

DOI: $10.23880 /$ oajds-16000243

\section{Abstract}

Polymethacrylate (PMMA) denture base material was used in dentistry for fabricating removable complete and partial dentures since 1936. Many investigators exposed the denture base and denture teeth, to colored foods, different beverages, mouthwashes, and different materials. Coffee is highly consumable drink in many parts of the world, especially in Saudi Arabia (KSA). Where it is consumed in modified version commonly known as "Gahwa" starts by adding coffee beans with cardamom powder in boiling water. The aim of the study was to evaluate the influence of normally made coffee in KSA, on PMMA denture base materials.

Materials and Methods: Samples were prepared from three different types of Denture base. Samples were divided into three groups depending on the types of denture base material. The coffee was prepared by adding 56 grams of Arabic coffee (Arabic Nescafe, Classic Nestle, Swiss) added in 2800 millimetre of boiling water and allowed to cool to $25^{\circ} \mathrm{C}$. The contents were filtered with filter paper. PPMA samples then immersed in containers containing $10 \mathrm{ml}$ of prepared coffee for 3 weeks. Daily fresh coffee was prepared for immersion of PPMA samples for staining. Colour analysis was carried out after 3 weeks. The color differences of specimens were assessed at the beginning and after 21st day of immersion. The Colorimeter (Shade Eye NCC; Shofu Dental Corporation, Kyoto, Japan) was calibrated as per the manufacturer's guidelines before analyzing color change of dried PMMA samples.

Results: It was observed that there was a significant difference compared with PMMA ( $\mathrm{P}<0.001)$ and Polyamid after analyzing of variance (ANOVA). Huge colour change observed with Polyamid resins when compared with PMMA resins.

Keywords: Arabian Coffee; Polymethacrylate; Denture base material 


\section{Open Access Journal of Dental Sciences}

Abbreviations: PMMA: Polymethacrylate; RPDs: Removable Complete \& Partial Dentures; ANOVA: Analysis of Variance.

\section{Introduction}

Polymethacrylate (PMMA) denture base material has been used many years ago in dentistry for fabricating removable complete and partial dentures a substitute for vulcanized rubber. This material had great success till date because of its technician friendly handling, clinically respectable thermal conductivity, less absorption of oral fluids and negligible change in color so it is highly esthetically acceptable by patients $[1,2]$.

For improvement of the mechanical characteristics of the resin, few alterations in the material composition along with numerous other fabricating methods have been attempted. Innovations to improve the strength, mechanical properties are still in progress [2]. The polymerization reaction of denture base resin to get the final prosthesis begins by combining monomer and polymer in the recommended proportion, followed by packing of resin, curing either by hot water bath or microwave [3].

Thermoplastic dentures were introduced as an alternative to PMMA [4]. Thermoplastic resins can be classified as thermoplastic acetal, thermoplastic acrylic, thermoplastic polycarbonates, and thermoplastic nylon $[5,6]$. Polyamide resin is produced by using an injection molding method, has recently been introduced. It is considered as high-quality elastic denture materials, as it has low solubility, high thermal resistance and flexibility, high strength, and superior moldability [7]. In literature, investigators exposed the denture base and denture teeth discoloration, to colored foods, different beverages, mouthwashes, polishing materials and concluded that PMMA staining is subject to the composition of PMMA, the environment in which it is used and manipulation during fabrication [8-12]. Coffee is highly consumable drink in many parts of the world, especially in Saudi Arabia. Where it is consumed in modified version commonly known as "Gahwa". The recipe starts by adding coffee beans with cardamom powder in boiling water allowing it to boil for few minutes before consuming with dates [13]. A significant colour exchange had been showed after dipping of the acrylic resin material in Espresso, Turkish and American cafe [14].

The aim of this study was to evaluate the effect of commonly used type of coffee, in Saudi Arabia, on different denture base materials.

\section{Materials and Methods}

In this study, samples $(25 \times 15 \times 2.5 \mathrm{~mm})$ of a heatpolymerizing hard PMMA (Dentaplast Opti- Press TM bredent GmbH \& Co.KG, Germany), thermoplastic PMMA (Polyan IC TM bredent GmbH \& Co.KG, Germany) and Polyamid (Deflex®, Nuxen S.R.L., Buenos Aires, Arjantin) denture materials were prepared. Polyamid is a thermoinjectable resin that falls in polymer series. Fifteen samples of each type were prepared and polished using no. 600 silicone carbide sand paper. Three groups of samples were divided depending up on the types of denture base.

\section{Samples Treatment}

The coffee was prepared by adding 56 grams of Arabic coffee (Arabic Nescafe, Classic Nestle, Swiss) added in 2800 millimeter of boiling water and allowed to cool to $25^{\circ} \mathrm{C}$. The contents were filtered with filter paper. PPMA samples then immersed in containers containing $10 \mathrm{ml}$ of prepared coffee for 3 weeks. Daily fresh coffee was prepared for immersion of PPMA samples for staining. Colour analysis was carried out after 3 weeks. Change in colour analysis of the samples was made at the middle of each sample. The color differences of specimens were assessed at the beginning and after $21^{\text {st }}$ day of immersion. Every time each sample was washed in water for 5 minutes and dried with paper towel before analyzing for color change. The Colorimeter (Shade Eye NCC; Shofu Dental Corporation, Kyoto, Japan) was calibrated as per the manufacturer's guidelines before analyzing the color changes of dried PMMA samples. The same investigator for flawless readings obtained the data.

\section{Statistical analysis}

The data collected for the change in colour were evaluated and compared for the different groups. By using analysis of variance (ANOVA) and Post Hoc Tukey's test at a significant level of $p<0.05$ comparing among the variable groupings, Colour exchange $\Delta \mathrm{E} *$ data had been analyzed.

\section{Results}

The values for maximum, minimum, mean as well as standard deviation for each group were demonstrated in the Table 1 and Figure 1. Colour changes of acrylic resin had been showed lower value after dipping in Arabian coffee. Greater colour change was observed with polyamid resins when compared with PMMA resins. It was observed that there was a significant difference in colour changes between different groups $(\mathrm{P}<0.001)$ after analyzing of variance (ANOVA) (Table 2). 
The maximum color change was detected with combination of gahwa \& Polyamide $(\Delta E=6.59)$. The minimal color change was noted with combination of gahwa \& PMMA $(\Delta \mathrm{E}=2.81)$.

\begin{tabular}{|c|c|c|c|c|}
\hline Material & Minimum & Maximum & Mean colour changes & 2.81 \\
\hline PMMA & 1.64 & 4.22 & 3.81 & 0.83 \\
\hline Thermoplastic PMMA & 2.64 & 6.22 & 0.81 \\
\hline Polyamide & 5.08 & 10.3 & 1.63 \\
\hline
\end{tabular}

Table 1: Mean colour changes.

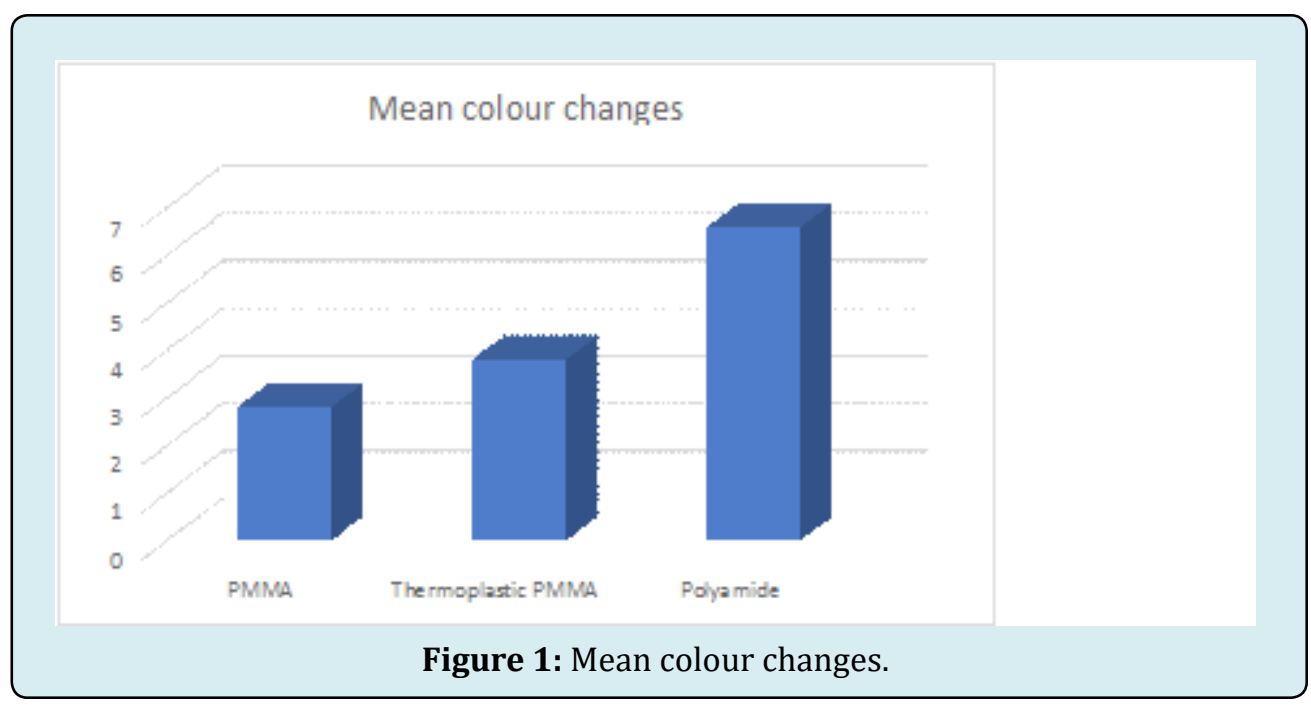

\begin{tabular}{|c|c|c|c|c|}
\hline Source of Variation & Sum of Squares & d.f. & Variance & F \\
\hline Between Groups: & 115.084 & 2 & 57.542 & 43.14 \\
\hline Within Groups & 56.0266 & 42 & 1.334 & \\
\hline Total: & 171.1106 & 44 & & \\
\hline
\end{tabular}

Post-hoc tests.

Tukey HSD Post-hoc Test...

Group 1 vs Group 2: Diff=1.0000, 95\%CI=-0.0246 to 2.0246, p=0.0570

Group 1 vs Group 3: Diff=3.7800, 95\%CI=2.7554 to $4.8046, \mathrm{p}=0.0000$

Group 2 vs Group 3: Diff $=2.7800,95 \% \mathrm{CI}=1.7554$ to $3.8046, \mathrm{p}=0.0000$

Table 2: ANOVA Test.

\section{Discussion}

The increasing demand of esthetics by edentulous and partially edentulous patients who wears removable complete \& partial dentures (RPDs) prosthesis forced clinicians to use minimum or some cases eliminate metal components that are used for retention of prosthesis [15].

The requirement of more esthetically pleasing materials like flexible acrylic is having limitations up to certain extend. Also, there is not much information made available by companies. In literature as well, it does not enlighten about chromatic stability \& microhardness.
Because of aging, flexible as well as conventional PPMA experienced change in colour due to intrinsic and extrinsic stains. Colour change with PMMA material resulted due to intrinsic stains involve variation with matrix of acrylic and interface with in fillers \& matrix [16].

Colour change of acrylic resin due to intrinsic staining may result in alteration of matrix. Whereas, absorption and adsorption that are considered as extrinsic factors for staining can also leads to colour change with acrylic resin $[17,18]$. In this research, analysis of change in colour of various denture 
base material after dipping in "gahwa" was carried out. And it was observed, the PMMA has higher colour stability when compared with Polyamid $(\mathrm{P}<0.001)$.

The auxochromes in association with chromophores with free radicals in gahwa, may leads to colour change of Polyamid [19]. The denture base material when exposed with tea or mouthwash shows more color stability when compared with Turkish coffee. Turkish coffee showed more discoloration of acrylic resin [20]. Chromatic variations were revealed in the specimen that was submerged in red wine, followed by coffee, this observation was done by SepúlvedaNavarro, et al. [21]. Encouragement for colour change by Cola was noted in Transflex material as well. The values of color changes converted to (NBS) National Bureau of Standard units showed them to be recognize to the human eye.

Aysan, et al. [22] concluded that the Polyamid denture base material stained more when introduced with various liquids consumed intraorally compared with PMMAmaterials. The highest color variation was detected in Polyamide \& coffee combinations. And lowest color variation was noted in PMMA. The prosthesis that are fabricated with Polyamid and used by the patients are mandatorily washed and cleaned thoroughly to avoid early staining of the prosthesis.

\section{Conclusion}

According to the results of the current study, we could conclude that the acrylic resin denture base material is the least denture base material affected by Arabian coffee among the tested groups.

\section{Acknowledgement}

This project was supported by the Deanship of Scientific Research at Prince Sattam Bin Abdulaziz University under the research project \# 2017/03/8149.

\section{References}

1. Phillips RW (1993) Skinner Dental materials, $9^{\text {th }}$ (Edn.), Rio de Janeiro: Guanabara Koogan.

2. John J, Gangadhar SA, Shah I (2001) Flexural Strength of Heat-Polymerized Polymethyl Methacrylate Denture Resin Reinforced with Glass, Aramid, or Nylon Fibers. Journal of Prosthetic Dentistry 86(4): 424-427.

3. Craig RC (1997) Prosthetic applications of polymers, $10^{\text {th }}$ (Edn.), Mosby, United States, pp: 500-551.

4. Kaplan P (2012) Flexible partial denture variations. The use of circumferential, combination, and continuous clasp designs. Dent Today 31(10): 138-141.
5. Shah VR, Shah DN, Chauhan CJ, Doshi PJ, Kumar A (2015) Evaluation of flexural strength and color stability of different denture base materials including flexible material after using different denture cleansers. J Indian Prosthodont Soc 15(4): 367-373.

6. Singh K, Aeran H, Kumar N, Gupta N (2013) Flexible thermoplastic denture base materials for aesthetical removable partial denture framework. J Clin Diagn Res 7(10): 2372-2373.

7. Soygun K, Bolayir G, Boztug A (2013) Mechanical and thermal properties of polyamide versus reinforced PMMA denture base materials. J Adv Prosthodont 5(2): 153-160.

8. Jang DE, Lee JY, Jang HS, Lee JJ, Son MK (2015) Color stability, water sorption and cytotoxicity of thermoplastic acrylic resin for non-metal clasp denture. J Adv Prosthodont 7(4): 278-287.

9. Liberman R, Combe EC, Piddock V, Watts DC (1996) Colour changes in acrylic teeth-comparison of an objective and subjective method. J Oral Rehabil 23(7): 464-469.

10. Rosentritt M, Esch J, Behr M, Leibrock A, Handel G (1998) In vivo color stability of resin composite veneers and acrylic resin teeth in removable partial dentures. Quintessence Int 29(8): 517-522.

11. Lee YK, Lim BS, Rhee SH, Yang HC, Powers JM (2004) Changes of optical properties of dental nano-filled resin composites after curing and thermo cycling. J Biomed Master Res B Appl Biomater 71(1): 16-21.

12. Lee SH, Lee YK, Lim BS (2004) Influence of the thermocycling on the optical properties of laboratory resin composites and an all-ceramic material. J Mater Sci Mter Med 15(11): 1221-1226.

13. Lee YK, Lim BS, Rhee SH, Yang HC, Powers JM (2005) Color and translucency of A2 shade resin composites after curing, polishing and thermocycling. Oper Dent 30(4): 436-442.

14. Harby N (2018) The effect of arabian coffee on acrylic denture base in comparison to other types of coffee. Bioscience Research 15(4): 3316-3321.

15. Wu JC, Latta GH, Wicks RA, Swords RL, Scarbecz M (2003) In Vitro Deformation of Acetyl Resin and Metal Alloy Removable Partial Denture Direct Retainers. J Prosthet Dent 90(6): 586-590.

16. Abu Bakr N, Han L, Okamoto A, Iwaku M (2000) Color Stability of Compomer after Immersion in Various 


\section{Open Access Journal of Dental Sciences}

Media. J Esthetic Dent 12(5): 258-263.

17. Wilson NH, Burke FJ, Mjör IA (1997) Reasons for Placement and Replacement of Restorations of Direct Restorative Materials by a Selected Group of Practitioners in the United Kingdom. Quintessence International 28(4): 245-248.

18. Villalta P, Lu H, Okte Z, Garcia Godoy F, Powers JM (2006) Effects of Staining and Bleaching on Color Change of Dental Composite Resins. J Prosthet Dent 95(2): 137142.

19. Takabayashi Y (2010) Characteristic of Denture Thermoplastic Resins for Non-Metal Clasp Dentures. Dent Mater J 29(4): 353-361.
20. Duymus ZY, Yanikoglu N, Arik M (2010) Evaluation of Colour Changed of Acrylic Resin Materials in the Different Solutions. Asian J Chem 22(9): 6669-6676.

21. Sepúlveda Navarro WF, Arana Correa BE, Borges CPF, Jorge JH, Urban VM, et al. (2011) Color Stability of Resins and Nylon as Denture Base Material in Beverages. J Prosthodontics 20(8): 632-638.

22. Aysan I, Uçar Y, Üşümez A (2011) Üç farklı kaide materyalinin farklı solüsyonlardaki renk stabilitesinin karşı- laştırılması A Comparison of the Color Stability of Three Different Base Materials in the Different Solutions. The Journal of Dental Faculty of Atatürk University 21: 219-225. 